\title{
STUDI POTENSI PEMBANGKIT LISTRIK TENAGA MIKRO HIDRO DI SUNGAI BRUKAH (KALI BENING, BANJARNEGARA)
}

\author{
Teguh Marhendi ${ }^{1}$, Toifin ${ }^{2}$ \\ ${ }^{12}$ Program Studi Teknik Sipil Fakultas Teknik Universitas Muhammadiyah Purwokerto
}

\section{Informasi Makalah}

Dikirim, 22 November 2018

Direvisi, 21 Januari 2019

Diterima, 30 April 2019

\section{Kata Kunci:}

Potensi PLTMH

Daya listrik

Sungai Brukah

\begin{abstract}
INTISARI
Kabupaten Banjarnegara memiliki Daerah Aliran Sungai yang berpotensi untuk Pembangkit Listrik Tenaga Mikro Hidro (PLTMH). Topografi wilayah berbentuk perbukitan dengan beda tinggi aliran sungai cukup curam berpotensi dapat menghasilkan energi listrik. Salah satunya adalah Sungai Brukah yang berada di Kali Bening, Banjarnegara. Tulisan ini bertujuan untuk mengetahui potensi Sungai Brukah untuk Pembangkit Listrik Tenaga Mikro Hidro (PLTMH). Analisis dilakukan terhadap kapasitas debit, tinggi jatuh efektif aliran, dan potensi daya listrik yang dapat dihasilkan. Metode yang diterapkan dalam analisis debit sungai dilakukan melalui metode profil sungai (cross section), Analisis dilakukan melalui pengukuran penampang vertikal sungai (profil sungai) dan kecepatan aliran air. Sedangkan analisis daya dan energi dihitung berdasarkan analisis debit tersedia (Q) dan tinggi jatuh efektif (Heff) pada potongan memanjang sungai dengan mempertimbangankan efisiensi turbin dan generator. Hasil analisis menunjukkan bahwa debit rerata Sungai Brukah terhitung sebesar 1,59 m3/dt dengan tinggi jatuh efektif aliran $50 \mathrm{~m}$ dan diperkirakan dapat menghasilkan daya listrik sebesar 510,440 kW.
\end{abstract}

\begin{abstract}
Banjarnegara district has a potential watershed for Micro Hydro Power (MHP). The topography of the hills shaped by the height difference is quite steep streams can potentially produce electrical energy. One of them is located in Brukah River Kali Bening, Banjarnegara. This paper aims to determine the potential of Brukah River for Micro Hydro Power Plant (PLTMH). The analysis is carried out on the discharge capacity, the high fall effective flow, and the potential of electrical power that can be generated. The method applied in the river flow analysis is done through the cross section method, the analysis is done through the measurement of river vertical sectional (river profile) and water flow velocity. While power and energy analysis is calculated based on available debit analysis $(Q)$ and high fall effective (Heff) on the longitudinal slice of the river by considering the efficiency of the turbine and generator. The analysis showed that the average river discharge Brukah accounted for $1.59 \mathrm{~m} 3 / \mathrm{sec}$ with high falls effective flow of $50 \mathrm{~m}$ and is expected to generate electrical power of $510,440 \mathrm{~kW}$.
\end{abstract}

\section{Korespondensi Penulis:}

Teguh Marhendi

Program Studi Teknik Sipil

Fakultas Teknik dan Sains

Universitas Muhammadiyah Purwokerto

Jl Raya Dukuhwaluh, Purwokerto, 53182

Email: tmarhendi@ump.ac.id 


\section{PENDAHULUAN}

Air merupakan sumber energi penting yang tidak hanya untuk memenuhi kebutuhan air, tetapi juga menjadi sumber energi pembangkit listrik. Indonesia adalah negara yang kaya sumber daya air sehingga sangat berpotensi untuk memproduksi energi listrik dari sumberdaya air baik skala besar maupun skala kecil. Salah satu Pembangkit Listrik yang dapat menggunakan energi air dalam skala kecil adalah Pembangkit Tenaga Mikro Hidro (PLTMH). Pembangkit listrik tipe ini merupakan alternatif sumber listrik energi terbarukan bagi masyarakat.

Kabupaten Banjarnegara memiliki Daerah Aliran Sungai yang berpotensi untuk Pembangkit Listrik Tenaga Mikro Hidro (PLTMH). Topografi wilayah berbentuk perbukitan dengan beda tinggi aliran sungai cukup curam berpotensi dapat menghasilkan energi listrik. Salah satunya adalah Sungai Brukah yang berada di Kali Bening, Banjarnegara. Disamping memiliki perbedaan elevasi aliran yang memadai antara hulu-hilir, daerah tangkapan air sungai tersebut memiliki hutan yang cukup terpelihara sehingga ketersediaan air cukup tersedia sepanjang tahun dengan karakteristik debit kontinyu. Beberapa penelitian lain penelitian ditekankan pada kajian kelayakan ekonomis PLTMH, potensi air terjun untuk PLTMH, serta kajian potensi berdasarkan curah hujan. Pada penelitian ini, analisis ditekankan pada potensi pembangkit listrik berdasarkan ketersediaan debit sepanjang tahun di Sungai Brukah.

Berdasarkan penelitian Wilda Faradina, Hadi Suyono, dan Teguh Utomo (2015), pada kajian kelayakan ekonomis Pembangkit Listrik Tenaga Mikro Hidro Gunung Sawur 1 dan Gunung Sawur 2 di Lumajang [1], diperoleh hasil bahwa daerah tersebut secara ekonomi layak untuk dibuat PLTMH. Parameter yang digunakan untuk analisis ekonomi energi adalah Pay Back Period (PBP), Net Present Value (NPV) dan Return Of Investment (ROI) dengan kondisi jika di kelola langsung oleh masyarakat atau dikelolah PT. PLN (Persero) (on grid). Hasil penelitian menunjukkan bahwa debit air sungai Besuk Semut mampu membangkitkan daya minimal sebesar 9,1408 kW Gunung Sawur 1 dan 3,2588 kW Gunung Sawur 2. Energi istrik yang dapat dibangkitkan pertahun sebesar 101478,33 kWh. Berdasarkan hasil perhitungan diperoleh biaya investasi yang dibutuhkan untuk mrealisasikan PLTMH Gunung Sawur sebesar Rp563.843.121, Net Present Value (NPV) jika di kelola PT. PLN (Persero) Rp 4.121.417.655, Net Present Value (NPV) jika di kelola masyarakat sebesar Rp1.166.816.006 pada alternatif 1 , Rp1.599.480.788 pada alternatif 2, Rp2.464.810.352 pada Alternatif 3,Pay Back Period (PBP) jika di kelola PT. PLN (Persero) 8,1 tahun, Pay Back Period (PBP) jika di kelola masyarakat 22 tahun pada alternatif 1, 17,6 tahun pada alternatif 2 dan 12,6 tahun pada alternatif 3. Dalam penelitian lain, Aprianto (2014) melakukan analisa potensi air terjun untuk Pembangkit Listrik Mikrohidro di Kawasan Wisata Girimanik [2]. Hasil penelitian ini menunjukkan bahwa air terjun memiliki kapasitas menghasilkan energi listrik sebesar 20,72 kW.

Doni Khaira Arya, 2012, melakukan analisis potensi Mikro Hidro berdasarkan curah hujan pada beberapa DAS di Jawa Barat [3]. Hasil penelitiannya menunjukkan bahwa masing-masing DAS memiliki kapasitas dan potensi menjadi PLTMH. Sementara itu, Gaina Saputra dan Amien Raharjo (2014) , melakukan studi potensi PLTMH di Kampung Nyomplong, Bogor [4] [10]. Hasil kajian menunjukkan bahwa potensi energi listrik yang dapat dimanfaatkan adalah $5 \mathrm{~kW}$ dan lebih besar dari kebutuhan listrik warga yaitu $2,358 \mathrm{~kW}$.

Pada penelitian lain, Arifin Matoka dan Yasin Muhammad (2008), melakukan kajian Potensi Energi Listrik Mikrohidro pada Saluran Irigasi Propinsi Gorontalo untuk Menunjang Elektrifikasi Pertanian [5] [13]. Hasil penelitian menunjukkan bahwa total daya yang diperoleh pada lokasi tersebut adalah sebesar $782,18 \mathrm{~kW}$.

\section{METODE PENELITIAN}

\subsection{Lokasi Penelitian}

Penelitian ini mengambil lokasi di Sungai Brukah Desa Kalibening Kecamatan Kalibening Kabupaten Banjarnegara yang berada pada posisi $07^{\circ} 13^{\prime} 57^{\prime \prime}$ LS dan $109^{\circ} 38^{\prime} 19^{\prime \prime} \mathrm{BT}$. 


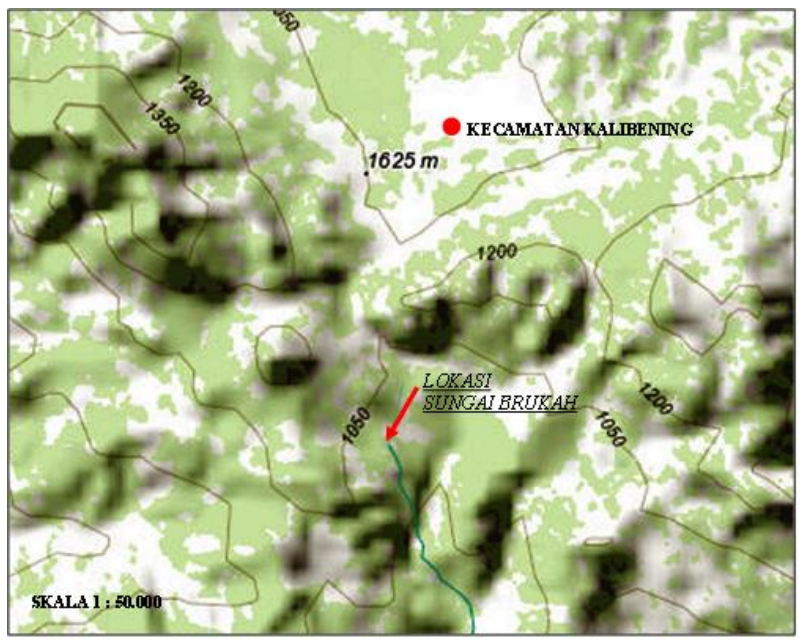

Gambar 1. lokasi Daerah penelitian (dokumentasi, 2017)

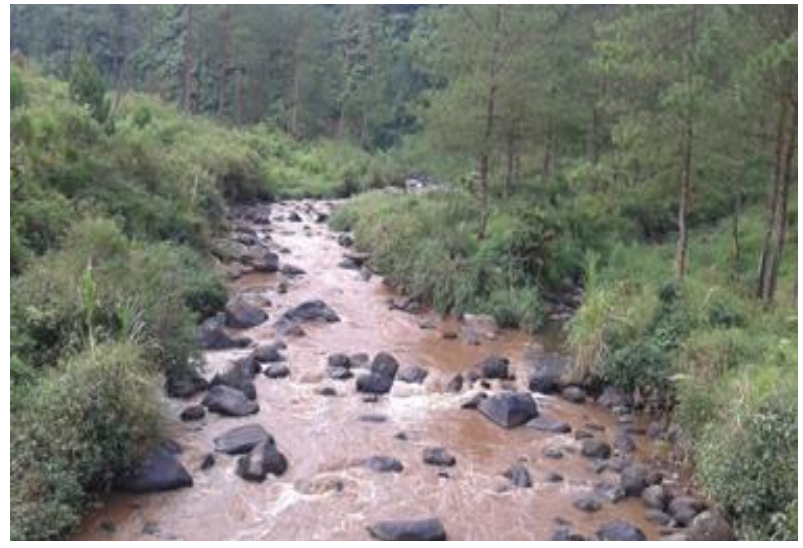

Gambar 2. Kondisi Aliran Sungai Brukah (dokumentasi, 2017)

Pada Gambar 1 menunjukkan lokasi penelitian berdasarkan peta RBI, sedang Gambar 2 menunjukkan kondisi lokasi yang digunakan penelitian.

\subsection{Analisis Debit Sungai}

Debit merupakan jumlah air yang mengalir di dalam saluran atau sungai per unit waktu. Metode yang umum diterapkan untuk menetapkan debit sungai adalah metode profil sungai (cross section). Pada metode ini debit merupakan hasil perkalian antara luas penampang vertikal sungai (profil sungai) dengan kecepatan aliran air.

$$
\mathrm{Q}=\mathrm{AV}
$$

dengan :

$\mathrm{Q} \quad=$ debit aliran $(\mathrm{m} 3 / \mathrm{s})$

A $\quad=$ luas penampang vertikal $(\mathrm{m} 2)$

$\mathrm{V}=$ kecepatan aliran sungai $(\mathrm{m} / \mathrm{s})$

\subsection{Analisis Debit Sungai}

Pada proses aliran perpipaan, energi potensial berangsur-angsur berubah menjadi energi mekanis. Pada kondisi ini air memutar roda turbin. Selanjutnya roda turbin yang dihubungkan dengan generator akan mengubah energi mekanis (gerak) menjadi energi listrik [6] [8] [9] [11] [12]. Analisis daya dan energi pada penelitian ini dihitung berdasarkan debit tersedia (Q) dan tinggi jatuh efektif (Heff) pada potongan memanjang sungai dengan mempertimbangankan efisiensi turbin dan generator, sebagimana persamaan (2) sampai (4). 


$$
\begin{gathered}
\text { Daya Teoritis }=9,81 \times \mathrm{P} \times \mathrm{Q} \times \mathrm{H}_{\mathrm{eff}}(w) \\
\text { Daya Turbin }=9,81 \times \rho \times \eta t \times \mathrm{Q} \times \mathrm{H}_{\mathrm{eff}}(w) \\
\text { Daya Generator }=9,81 \times \rho \times \eta g \times \eta t \times \mathrm{Q} \times \mathrm{H}_{\mathrm{eff}}(w)
\end{gathered}
$$

dengan :

$$
\begin{array}{ll}
\mathrm{P} & =\text { daya yang dihasilkan }(\mathrm{kW}) \\
\eta t & =\text { efisiensi turbin }(\mathrm{rpm}) \\
\eta g & =\text { efisiensi generator }(\mathrm{rpm}) \\
\rho & =\text { massa jenis air }=1000(\mathrm{~kg} / \mathrm{m} 3) \\
\mathrm{Q} & =\text { debit pembangkit }(\mathrm{m} 3 / \mathrm{dtk}) \\
\mathrm{H}_{\mathrm{eff}} & =\text { tinggi jatuh efektif }(\mathrm{m}
\end{array}
$$

\section{HASIL DAN PEMBAHASAN}

\subsection{Analisis Debit Sungai}

\begin{tabular}{|c|c|c|c|c|c|c|}
\hline \multicolumn{7}{|c|}{ Lebar Sungai } \\
\hline 0 & 1 & 2 & 3 & 4 & 5 & 6 \\
\hline 0,18 & & & & & & \\
\hline 0,38 & & & $=$ & $=$ & & \\
\hline 0,42 & & & & & & \\
\hline 0,44 & & & & & & \\
\hline 0,64 & & & & & & \\
\hline 0,67 & & & & & & \\
\hline 0,71 & & & & & & \\
\hline
\end{tabular}

Debit sungai di analisis dengan menentukan luasan profil melintang potongan sungai (cross section) dan menentukan kecepatan aliran pada segmen sungai tersebut. Pada penelitiasn ini debit merupakan hasil perkalian antara luas penampang vertikal sungai (profil sungai) dengan kecepatan aliran air sebagaimana tampak pada Gambar 3 di bawah ini.

$$
\mathrm{Q}=\mathrm{AV}
$$

dengan :

$\begin{array}{ll}\mathrm{Q} & =\text { Debit aliran }(\mathrm{m} 3 / \mathrm{s}) \\ \mathrm{A} & =\text { Luas Penampang Vertikal }(\mathrm{m} 2) \\ \mathrm{V} & =\text { Kecepatan Aliran Sungai }(\mathrm{m} / \mathrm{s}) .\end{array}$

Gambar 3. Profil Melintang Sungai Brukah pada salah satu segmen (Analisis, 2018)

Kecepatan Aliran

Pengukuran kecepatan aliran dilakukan dengan metode apung (floating method) pada jarak $10 \mathrm{~m}$ memanjang sungai. Pemilihan tempat pengukuran dilakukan pada segmen sungai yang relatif lurus dengan tidak banyak arus yang tidak beraturan. Pengukuran dilakukan beberapa kali sehingga dapat diperoleh kecepatan rata-rata permukaan aliran sungai sesuai persamaan (6) dan Tabel 1.

dengan :

$$
\mathrm{V}=\mathrm{L} / \mathrm{t}
$$

$\mathrm{L}=$ jarak antara dua titik pengamatan $(\mathrm{m})$

$\mathrm{t}=$ waktu perjalanan benda apung (detik) 
Tabel 1. Kecepatan Aliran beberapa segmen Sungai Brukah

\begin{tabular}{cccc}
\hline $\begin{array}{c}\text { Pias/ Segmen } \\
\text { Sungai }\end{array}$ & Jarak L (m) & $\begin{array}{c}\text { Waktu } \\
\text { (detik) }\end{array}$ & $\begin{array}{c}\text { Kecepatan V } \\
\text { (detik) }\end{array}$ \\
\hline A1 & 2,000 & 0,870 & 2,300 \\
A2 & 2,000 & 0,922 & 2,170 \\
A3 & 2,000 & 1,235 & 1,620 \\
A4 & 2,000 & 1,333 & 1,500 \\
A5 & 2,000 & 1,538 & 1,300 \\
A6 & 2,000 & 1,111 & 1,800 \\
\hline
\end{tabular}

Sumber: Analisis, 2015

Berdasarkan analisis dari Tabel 1 di atas, diketahui rata-rata debit aliran sungai Brukah mencapai 1,59 $\mathrm{m} 3 /$ detik.

\subsection{Tinggi Jatuh Air}

Pengukuran tinggi jatuh air menuju rencana lokasi turbin dilakukan dengan acuan topografi sungai menggunakan aplikasi Global Mapper Versi 16 didukung Aplikasi Altimeter. Prinsip kerja altimeter adalah mengukur tekanan udara. Altimeter sangat mudah terpengaruh oleh perubahan suhu, tekanan atmosfer dan kelembaban (Gambar 4). Pemakaian Altimeter biasanya selalu diikuti dengan pemakaian kompas. Altimeter bekerja berdasar tekanan udara sesuai naiknya angka ketinggian. Jika alat ini akan dipakai sebaiknya jangan dimasukkan kedalam tas/ransel karena hal tersebut bisa mempengaruhi prinsip kerja altimeter. Salah satu keuntungan menggunakan alat ini adalah sangat peka terhadap guncangan, perubahan cuaca serta perubahan temperatur. Kekurangan alat ini adalah bahwa Altimeter yang bekerja mengukur ketinggian dengan cara mengukur tekanan udara harus terus dipantau karena tekanan udara terus berfluktuasi di seluruh permukaan bumi karena adanya perubahan cuaca. Kekurangan lainnya adalah altimeter berbasis tekanan udara adalah tidak memperhitungkan hambatan berbahaya seperti gunung atau bangunan.
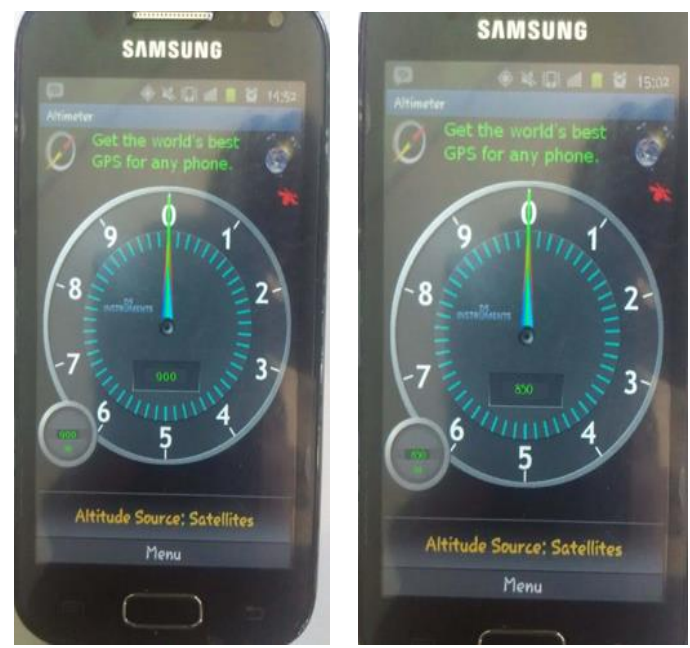

Gambar 4. Altimeter [6]

\subsection{Daya dan energi}

Daya listrik yang dihasilkan turbin, sangat dipengaruhi oleh besarnya debit aliran menuju turbin dan jenis turbin yang sesuai dengan kondisi sungai tersebut. Untuk mengetahui jenis turbin yang sesuai, perlu ditinjau hubungan tinggi jatuh air dengan tipe turbin yang tersedia (Arismunandar, Artono, 1991) seperti tampak pada Gambar 5 di bawah ini. 


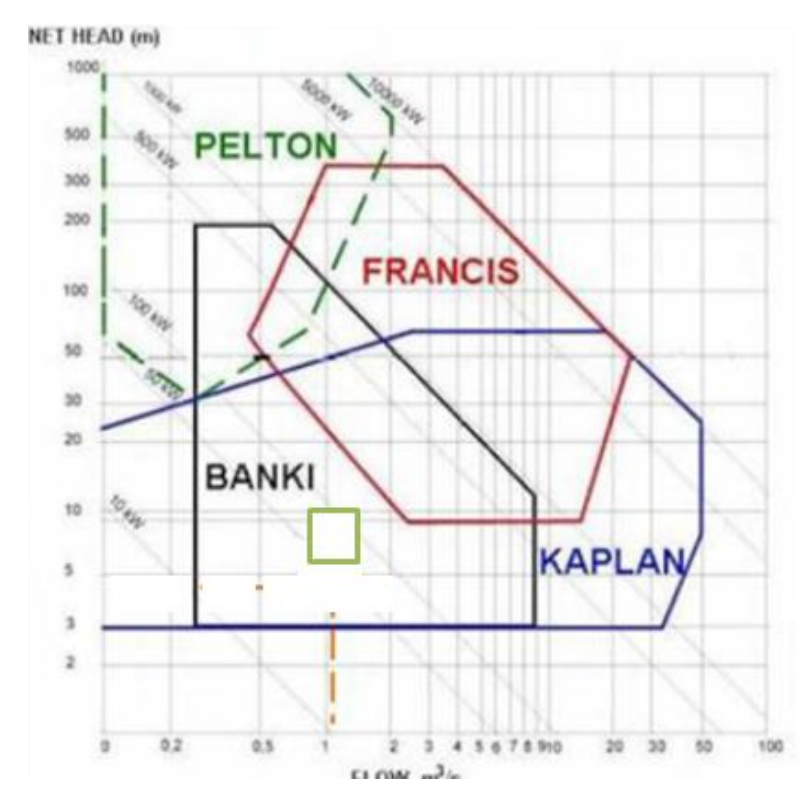

Gambar 5. Penentuan tipe turbin terhadap tinggi jatuh dan debit Sumber : Patty, O., Tenaga Air, 1995 [7]

Dari hasil pengukuran menggunakan Gambar 5 diatas diketahui bahwa tinggi jatuh efektif pada lokasi penelitian adalah 50 meter dengan debit rata-rata sungai sebesar 1,59 m3/dt. Tinggi jatuh efektif yang ditunjukkan dalam penelitian ini dapat terjadi dibeberapa lokasi segmen sungai, mengingat kondisi topografi sungai yang cenderung curam disepanjang sungai dibagian hulu. Artinya untuk pemilihan lokasi rencana penempatan turbin, dapat menyesuaikan dengan topografi sungai yang memungkinkan dengan tinggi jatuh tersebut, namun perlu dipertimbangkan dengan jarak atau lokasi wilayah yang akan mendapatkan daya dari trubin tersebut.

Dengan dasar hasil pengukuran tinggi jatuh efektif tersebut, dipilih turbin tipe Banki/Crossflow. Turbin tipe ini memiliki spesifikasi head berkisar 5-200 m, debit berkisar 0,03-16 m³/dt dan kapasitas 10$7000 \mathrm{~kW}$ serta efisiensi turbin 0,77. Prinsip turbin Crossflow adalah radial, turbin bertekanan kecil dengan injeksi tangensial dari putaran kipas dengan poros horisontal. Turbin ini digolongkan sebagai turbin berkecepatan rendah dengan spesifikasi operasi turbin seperti di bawah ini.

a. Tinggi terjunan (head) :

b. Debit :

$$
\mathrm{H}=5 \text { meter }-200 \text { meter }
$$

$$
\mathrm{Q}=0,03 \mathrm{~m} 3 / \mathrm{dt}-13 \mathrm{~m} 3 / \mathrm{dt}
$$

c. Kapasitas :

$$
\mathrm{N}=10 \mathrm{~kW}-3500 \mathrm{~kW}
$$

Efisiensi turbin dan generator terpakai adalah:

Efisiensi turbin, $\eta t \quad=0,77$

Efisiensi generator, $\eta g=0,85$

Menggunakan data di atas, daya listrik yang dibangkitkan dapat dihitung dengan memakai persamaan :

$$
\begin{aligned}
\text { Daya Turbin } & =9,81 \times \mathrm{Q} \times \text { Heff } \times \eta t \\
& =9,81 \times 1,59 \times 50 \times 0,77 \\
& =600,52 \mathrm{~kW} \\
\text { Daya Generator } & =\text { Daya turbin } \times \eta g \\
& =600,52 \times 0,85 \\
& =510,44 \mathrm{~kW}
\end{aligned}
$$

Berdasarkan analisis di atas menunjukkan bahwa debit rerata Sungai Brukah terhitung sebesar 1,59 m3/dt dengan tinggi jatuh efektif aliran $50 \mathrm{~m}$ dan diperkirakan dapat menghasilkan daya listrik sebesar 510,440 
kW. Daya sebesar terhitung tersebut, dapat asumsikan untuk dimanfaatkan bagi pemenuhan kebutuhan listrik di beberapa wilayah atau masyarakat dengan perkiraan, jika tiap KK menggunakan daya 900W, maka daya tersebut dapat diasumsikan untuk memenuhi sekitar $450 \mathrm{KK}$.

\section{KESIMPULAN}

Berdasarkan hasil analisis dapat diambil kesimpulan Sungai Brukah memiliki potensi untuk PLTMH dengan perkiraan menghasilkan daya listrik sebesar 510,440 kW.

\section{DAFTAR PUSTAKA}

[1] Wilda Faradina, Hadi Suyono, dan Teguh Utomo, 2015, Kajian Kelayakan Ekonomis Pembangkit Listrik Tenaga Mikro Hidro Gunung Sawur 1 dan Gunung Sawur 2 Di Lumjang, Jurnal Elektro, UB, Vol 3 No. 1, 2015

[2] Aprianto, 2014,Analisa Potensi Air Terjun Untuk pembangkit Listrik Mikrohidro Di Kawasan Wisata Girimanik, Tugas Akhir, Jurusan Teknik Elektro, Fakultas Teknik, UMS, Surakarta

[3] Doni Khaira Arya, 2012, Analisis Potensi Mikro Hidro Berdasarkan Curah Hujan, Program Studi Meteorologi, Fakultas Ilmu dan teknologi Kebumian, ITB, Bandung

[4] Gaina Saputra, Amien Raharjo, 2014, Studi Potensi PLTMH Kampung Nyomplong, Bogor, Jurusan Teknik Elektro Fakultas Teknik, UI, Jakarta

[5] Arifin Matoka dan Yasin Muhammad, 2008, Kajian Potensi Energi Listrik Mikrohidro pada SaluranIrigasi Propinsi Gorontalo untuk Menunjang Elektrifikasi Pertanian, Jurusan Teknik Elektro, Universitas Gorontalo

[6] Arismunandar, Artono. 1991. Buku Pegangan Teknik Tenaga Listrik I, PT. Pradnya Paramita. Jakarta

[7[ Patty, O. 1995, Tenaga Air, Erlangga. Jakarta

[8] Verry Dwiyanto, 2016, Analisis Pembanhgkit Listrik Tenaga Mikro Hidro (PLTMH) Studi Kasus: Sungai Air Anak (Hulu Sungai Way Besai), Universitas Lampung

[9] Parabelen T.D. Rompas, 2011, Analisis Pembangkit Listrik Tenaga Mikro Hidro (PLTMH) Pada Daerah Aliran Sungai Ongkak Mongondow Di Desa Muntoi, Kabupaten Bolaang Mongondow, Jurnal Penelitian Saintek, Volume 16 No. 2 Tahun 2011

[10] Fandi S.M. Tambunan, Rudy Setyabudi, 2014, Analisis Kelayakan Pembangunan Pembangkit Listrik Tenaga Mikro Hidro (PLTMH), di Desa Nyomplong, Bogor, Universitas Indonesia, Jakarta

[11] Nan Andy Wibowo, Verry Dermawan, dan Doni Harisuseno, 2011, Studi Perencanaan Pembangkit Listrik Tenaga Mikro Hidro (PLTMH) Wamena Kaputaen Jaya Wijaya Propinsi Papua, Jurusan Teknik Pengairan Universitas Brawijaya, Malang

[12] Fatma Nurkhaerani, 2016, Perancangan Pembagkit Listrik Tenaga Mikro Hidro (PLTMH) di Sungai Cikaniki, Desa Malasari, Kecamatan Nanggung, Kabupaten Bogor, Depatemen Teknik Sipil dan Lingkungan Institut Teknologi Pertanian Bogor, Bogor

[13] Purbo Adi Wicaksono, Maman Somantri dan Djoko Windarto, 2013, Sistem Informasi Potensi dan Analisa Perencanaan Pembangkit Listrik Tenaga Mikro Hidro (PLTMH) di Indonesia Menggunakan Pemrograman PHP, Transient, Vol 2 No 2 Juni 2013, ISSN: 2302-9927, 381 